\section{Alternativa al cierre de heridas crónicas mediante injertos de Reverdin y factores de crecimiento en cirugía menor ambulatoria}

\section{Alternative to chronic wound closure by Reverdin grafts and growth factors in ambulatory surgery minor}

Francisco Javier Pérez Vega ${ }^{1}$

María Teresa Gutiérrez Vázquez²

José Ramón Lorenzo Peñuelas ${ }^{3}$

Juan Francisco Domínguez Bermúdez ${ }^{4}$

José Carlos Armario Hita ${ }^{5}$

Guillermo de Castro Maqueda ${ }^{6}$

1. Enfermero. Hospital Universitario de Puerto Real (Cádiz).

2. Licenciada en Química. Universidad de Cádiz.

3. Doctor en Medicina. Profesor de Farmacología clínica. Facultad de Enfermería y Fisioterapia. Universidad de Cádiz.

4. Médico especialista en Cirugía Ortopédica y Traumatología. Hospital Universitario de Puerto Real (Cádiz).

5. Doctor en Medicina. Especialista en Dermatología y Venereología. Hospital Universitario de Puerto Real (Cádiz).

6. Doctor en Medicina del Deporte. Profesor de la Facultad de Ciencias del Deporte. Universidad Pablo de Olavide (Sevilla).

\section{Correspondencia:}

Francisco Javier Pérez Vega

Unidad de Cirugía Ortopédica y Traumatología

Hospital Universitario de Puerto Real (Cádiz)

Crta. Nacional IV, km 665

11510 Puerto Real (Cádiz)

Tel. 956005464

E-mail: fjperez11@gmail.com

\section{RESUMEN}

El cierre de heridas crónicas supone una alta tasa en cuidados de enfermería, sobre todo en heridas de difícil cicatrización, debido a la falta de respuesta a los tratamientos aplicados y a la elevada prevalencia del proceso. Es necesario encontrar un método que reduzca el tiempo de curación, evite las complicaciones inherentes al cierre por cura húmeda convencional y pueda realizarse con los recursos disponibles en cualquier medio sanitario.

El plasma rico en plaquetas (PRP) autólogo se utiliza actualmente como alternativa a la infiltración tradicional con corticoesteroides o en estado gel, en la cobertura o relleno de una determinada zona con pérdida de tejido. El presente estudio combina el uso de PRP e injertos insulares descritos por Reverdin (1869), en 15 individuos que presentan traumatismos con pérdida de sustancia que no responden a la cura húmeda convencional.

Los resultados muestran que, tras la primera aplicación de PRP, se aprecia la aparición de tejido de granulación, que es susceptible

de recibir el injerto. La combinación de ambas técnicas acorta el período de cicatrización de las heridas tratadas, con equipos de fácil

accesibilidad en cualquier centro sanitario, minimizando costes con una expectativa de curación elevada, sumado al procedimiento fácilmente asumible por el personal de enfermería dedicado a cirugía menor ambulatoria.

PALABRAS CLAVE: cicatrización de heridas crónicas, cura de heridas, plasma rico en plaquetas, injertos de piel, cirugía menor ambulatoria.

\section{ABSTRACT}

The closure of chronic wounds by secondary intention, is a high rate of nursing, especially in poorly healing wounds, for two main reasons, the lack of response to treatments, and the prevalence of this appeal process as claimed in primary health care centers and outpatient hospital. Also, the patient can lead to a delay in their total healing (medical discharge), which sometimes induce other incidents such as ambulance, delay in job placement, etc. It is necessary to find a method which reduces healing time in these cases and at the same time, avoid the complications inherent to conventional wet cure closing and in turn, be available to the media and resources available on our health system. The application of Platelets Rich Plasma (PRP), obtained by centrifugation of blood drawn directly to the patient, has been running for nearly twenty years in the health care setting. It is currently used as an alternative to traditional infiltration corticosteroid tendinopathies in gel state or as a clot, equivalent to a mesh of fibrin membranes capable of forming, filling in coverage or a particular area of tissue loss.

Already in 1869, coined the term Reverdin island of skin grafts, initially in treating injury due to burns. In this technique, the wound is covered partially with small fragments of healthy skin of the patient. This study combines the use of PRP and slips island, applied in 15 individuals with trauma with loss of substance, no relevant medical history and do not respond to conventional wet cure. The results show that after the first application of the gel of PRP shows the appearance of granulation tissue, which is susceptible to grafting or island nested. The combination of both techniques shortens the healing time of wounds treated with equipment that is easily accessible in any health center, which is a very low level of spending and an expectation of success High cure, plus the procedure easily manageable by the nursing staff dedicated to program minor outpatient surgery.

KEYWORDS: healing of chronic wounds, wound healing, platelets rich plasma, skin grafts, minor outpatient surgery. 


\section{У INTRODUCCIÓN}

El cierre prolongado de las heridas crónicas ${ }^{1}$ de difícil cicatrización es una respuesta terapéutica deficiente a la curación de estas ${ }^{2}$ y representa una importante prevalencia en los cuidados de enfermería, tanto en el primer eslabón asistencial como en hospitales.
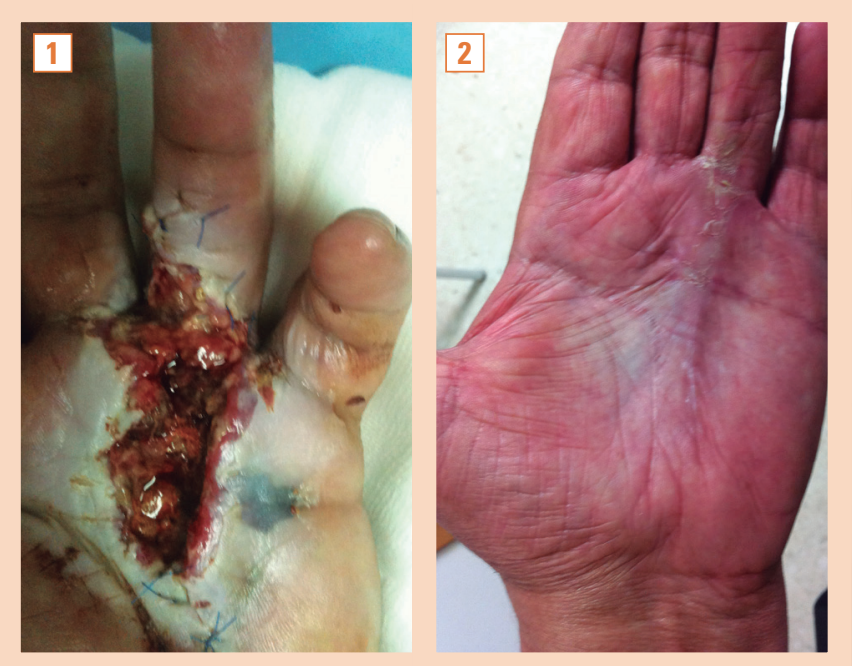

Figura 1 y 2. Enfermedad de Dupuytren.

En 1869, Reverdin ${ }^{3}$ comenzó a utilizar autoinjertos de piel completa del propio paciente para el cierre de heridas, extirpando con el bisturí fragmentos circulares de piel sana, para realizar una especie de "siembra" de estos fragmentos en el lecho de la herida crónica 4 . Por otra parte, el uso de plasma rico en factores de crecimiento (PRGF, Plasma Rich in
Growth Factors), derivados de plaquetas autólogas, es una terapia cada vez más utilizada en cirugía ${ }^{5-7}$, traumatología $a^{8,9}$ y medicina deportiva ${ }^{10}$. Tras los trabajos de Cohen y Levi-Montalcini (1948), se descubren en la década de 1990 los primeros PRGF ${ }^{11,12}$ y su aplicación en otros campos de la medicina ${ }^{13}$.

Actualmente, el plasma rico en plaquetas (PRP) se define como un plasma que contiene mayor cantidad de plaquetas que en sangre periférica $^{14}$, y su uso está cada vez más extendido en técnicas de regeneración y reparación tisular, incluido el cierre de heridas crónicas ${ }^{8}$. Los factores de crecimiento contenidos en el PRP estimulan la formación de matriz extracelular y la proliferación de células mesenquimatosas en las etapas iniciales del proceso de reparación tisular ${ }^{15}$.

El objetivo del presente trabajo es medir el tiempo necesario para el cierre de la herida crónica de difícil cicatrización, es decir, la epitelización, y confirmar su eficacia, asociando en el mismo paciente la aplicación de injertos insulares (Reverdin) y PRP (figs. 3-9).

\section{У MATERIAL Y MÉTODO}

Estudio cuasi-experimental, prospectivo de serie de casos, de un ańo de duración (septiembre de 2011 a octubre de 2012), realizado en la Unidad de Gestión Clínica de Cirugía Ortopédica y Traumatología (UGCCOT) del Hospital Universitario de Puerto Real (HUPR), Cádiz, y llevado a cabo sobre una población de 15 pacientes, elegidos mediante muestreo consecutivo, todos ellos intervenidos en dicha unidad clínica o diagnosticados por el Servicio de Dermatología del HUPR y derivados a sala de curas de traumatología para el seguimiento de su lesión crónica.

El HUPR ofrece asistencia sanitaria especializada en el Distrito Sanitario Bahía de Cádiz-La Janda, con una población de referencia de 326674 habitantes censados. La UGC-COT ha atendiendo en este mismo período a un 9,45\% de dicha población ( $\mathrm{n}=30$ 921), según expresan los datos del Instituto Nacional de Estadística y el Servicio de Documentación e Información del HUPR.

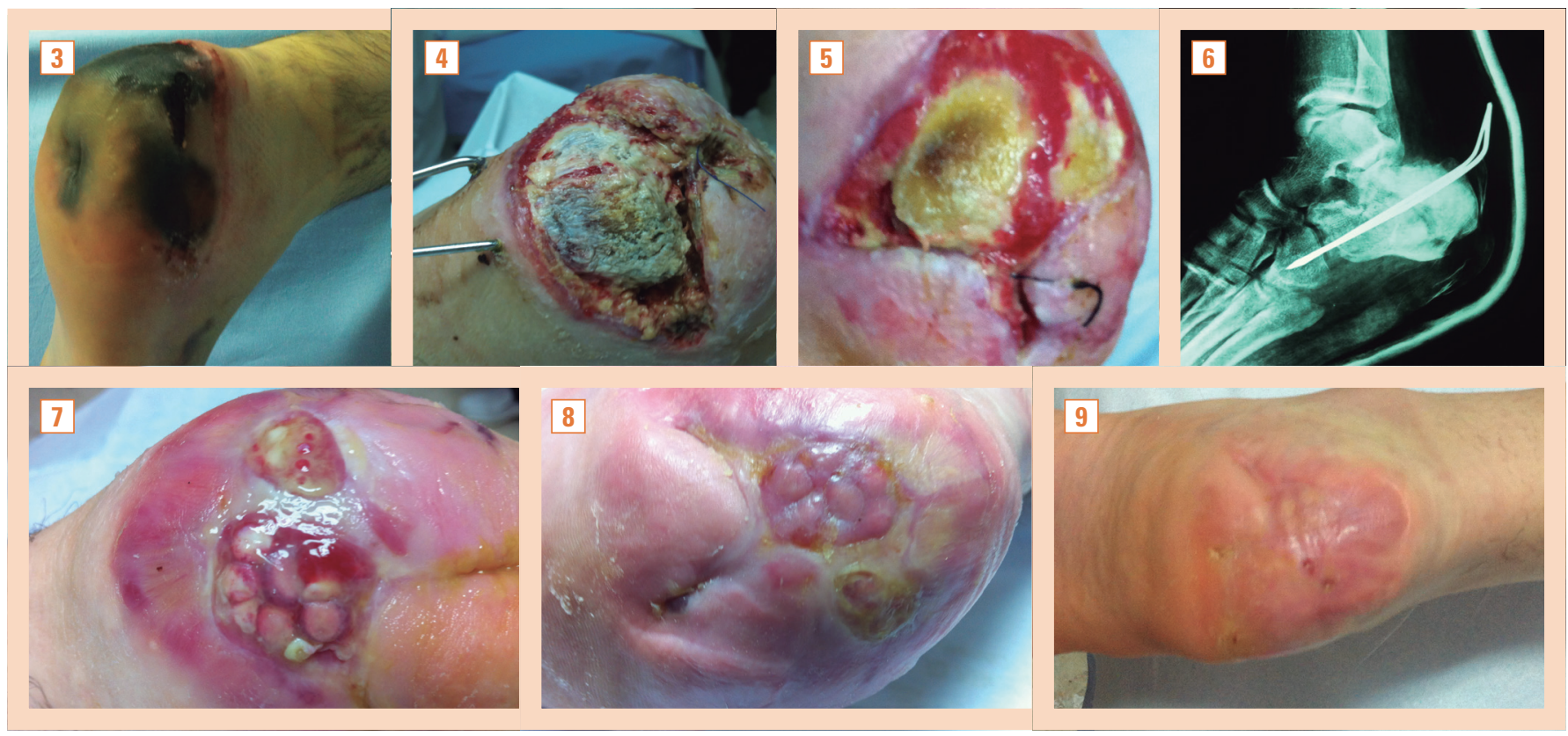

Figuras 3 a 9. Fractura de calcáneo de origen traumático, con necrosis tisular amplia de toda la región del talón. Reducción con AK y proceso de reparación mediante aplicación de plasma rico en plaquetas y colocación de injertos de Reverdin. 


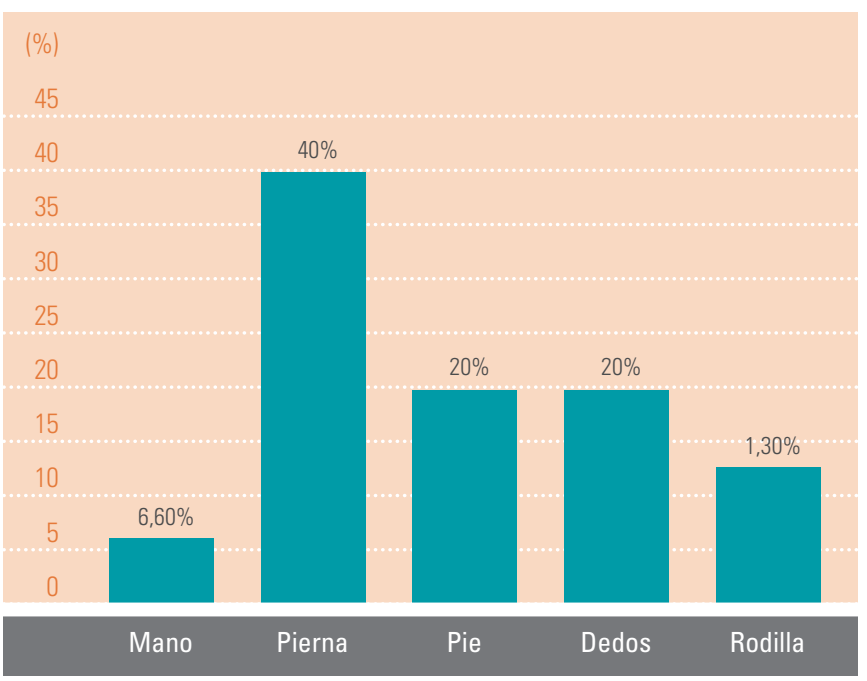

Figura 10. Distribución por regiones anatómicas.

Los pacientes presentaban heridas crónicas, con pérdida de espesor total o parcial de piel, que no respondían al tratamiento convencional (cura húmeda), de etiología traumática, con más de 30 días de evolución. La distribución de la región anatómica tratada con mayor porcentaje (40\%) corresponde a la región tibial (v. fig. 10). Representa la distribución por regiones anatómicas de las zonas tratadas.

Los motivos de exclusión fueron:

- Antecedentes de enfermedad neoplásica.

- Trombocitopatogenia.

- Déficit vascular asociado.
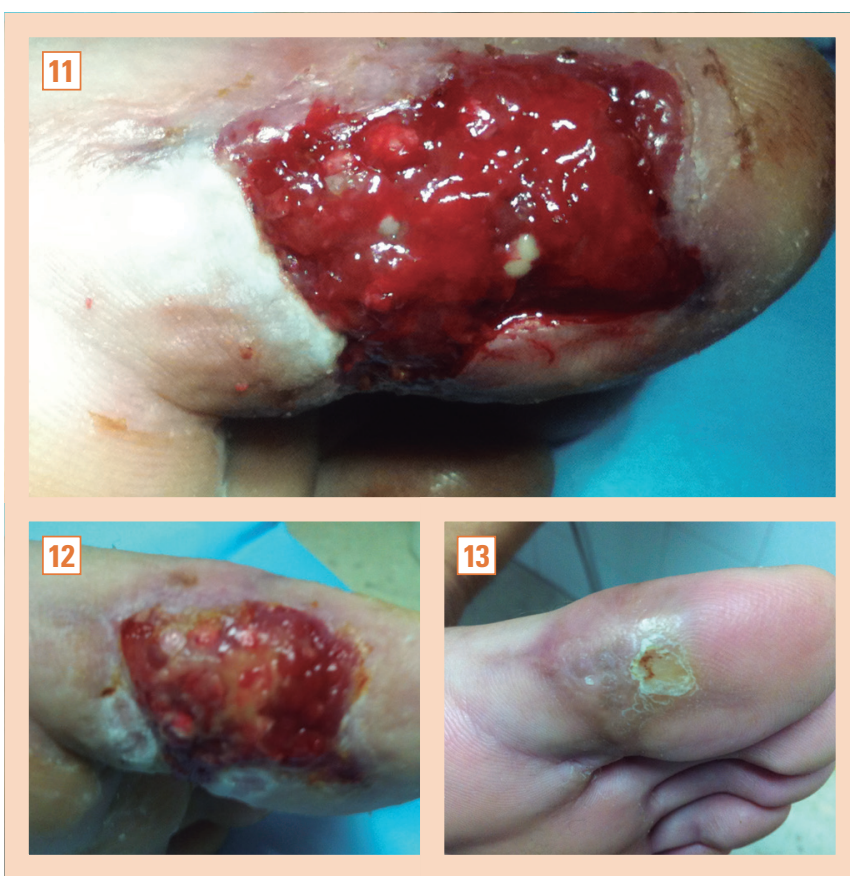

Figuras 11 a 13. Pérdida de sustancia en pulpejo del primer dedo del pie de origen traumático. Cierre con injertos de Reverdin y plasma rico en plaquetas.
A cada paciente se le recaba el consentimiento informado, modelo elaborado para tal fin.

\section{Obtención del plasma rico en factores de crecimiento}

El método utilizado para la obtención del PRGF es el denominado "de tubo". Consiste en la extracción de sangre periférica mediante el sistema Vacutainer ${ }^{\oplus}$, mediante aguja "Butterfly" $21 \mathrm{G}$ y campana desechable. Se extrae un volumen aproximado de 40-50 $\mathrm{ml}$ de sangre en tubos de citrato sódico ${ }^{16}$ de $4,5 \mathrm{ml}$. Inmediatamente se centrifuga (centrífuga JP-Selecta Mixtasel, modelo BL), en una doble centrifugación ${ }^{17}$, la primera a baja velocidad (1300 rpm/4 min), para la decantación de células, y una segunda, a velocidad más alta (3300 rpm/7 min), con la que se obtiene un poco más del doble de plaquetas que en condiciones basales (fig. 14). La separación del PRP se consigue por pipeteado directo, recogiendo el tercio de fracción del fondo del tubo. Para su activación, se añaden $0,5 \mu \mathrm{l}$ de cloruro de calcio al $10 \%{ }^{18}$ por cada mililitro de PRP. Una vez formado el coágulo, se aplica sobre el lecho de la herida previamente preparado $^{19}$.

\section{Obtención de los injertos de Reverdin}

La zona donante se establece en regiones anatómicas sin compromiso estético (nalgas y cara externa del muslo). Tras infiltración de anestésico local (mepivacaína al 2\% sin vasoconstrictor), se realiza la extracción con sacabocados dermatológico (punch) de los n. ${ }^{\text {os }} 3-5$.

Se colocan los injertos sobre una gasa empapada en solución de polihexanida y betaína al $0,1 \%$, en número variable (generalmente entre 6 y 18 islotes de piel). La zona donante se cierra mediante sutura directa. Los islotes de piel se preparan separando la grasa con tijeras finas. Solo conservamos para su implante la capa dermoepidérmica. Se prepara un apósito de colágeno liofilizado y celulosa oxidada regenerada, apósito colágeno-(COR) con las medidas correspondientes al contorno del lecho de la herida. Este apósito se taladra con el mismo punch, consiguiendo el nido correspondiente donde se van a colocar los injertos insulares.

\section{Preparación del lecho de la herida}

Desbridamiento del lecho y los bordes de la herida para que estén libres de tejidos necróticos, esfacelos y sin manifestaciones clínicas de infección ${ }^{20}$. Descontaminamos el lecho mediante lavado con solución de polihexanida y betaína al $0,1 \%$, dejando empapada una gasa estéril durante 5-10 min a la espera del procedimiento (figs. 15 y 16$)$.

\section{Aplicación de los injertos}

Aplicamos el coágulo de PRGF en el lecho limpio, sobre él colocamos el apósito de colágeno-(COR) y en los nidos introducimos los injertos con la superficie cutánea hacia arriba. Cubrimos todo con apósito de malla de silicona y sobre él, una espuma de poliuretano absorbente (figs. 17 y 18). Cerramos mediante vendaje semioclusivo del miembro, que debemos respetar al menos 7 días, si no existen complicaciones como dolor excesivo, intenso exudado, inflamación aparente, parestesias, fiebre y/o mal estado general o algún otro síntoma que nos haga sospechar una posible mala evolución. No debe manipularse el apósito de colágeno-COR, por ser reabsorbible por completo, conservando en su sitio cada islote implantado. 


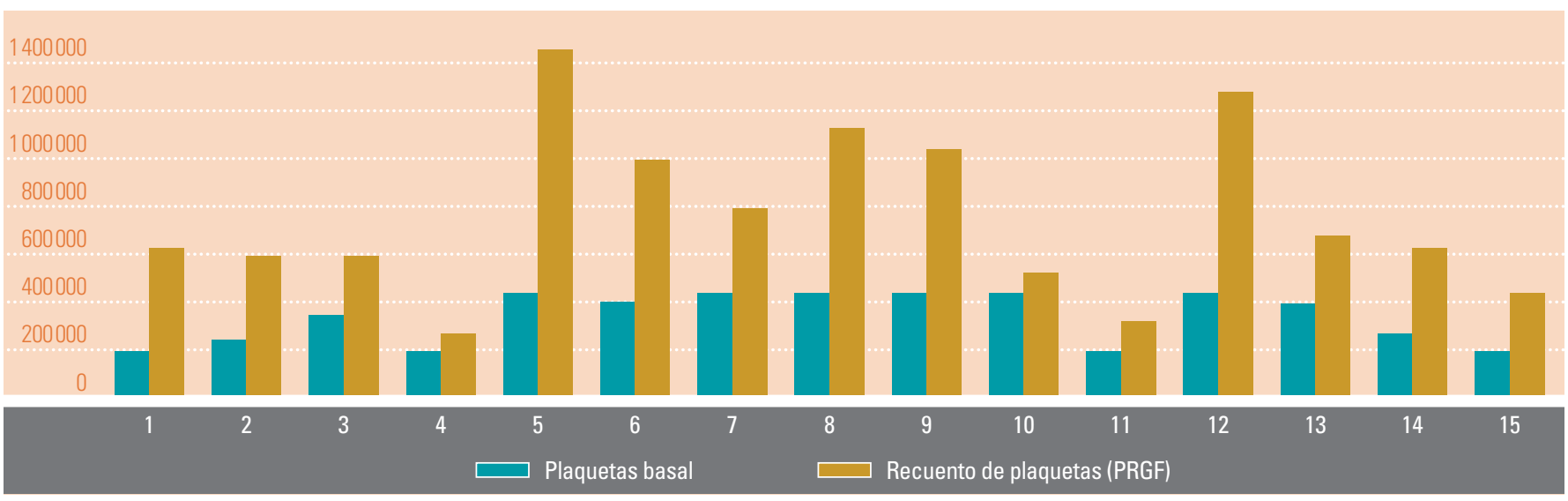

Figura 14. Comparativa de recuento plaquetario obtenido en sangre total y en plasma rico en plaquetas.

PRGF: plasma rico en factores del crecimiento.
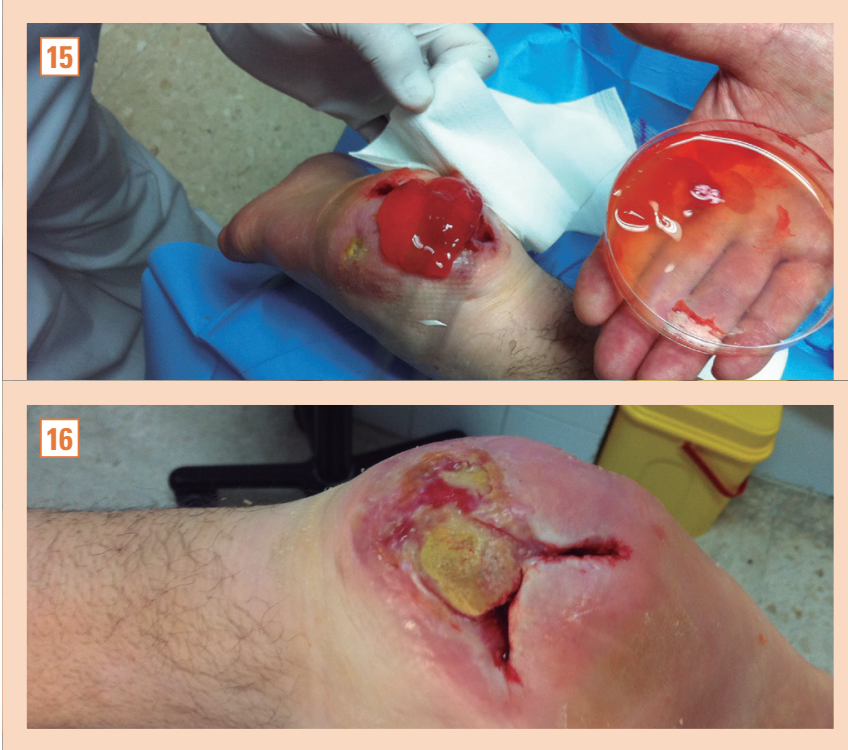

Figuras 15 y 16. Preparación del lecho de la herida y aplicación del gel de plasma rico en plaquetas.

La zona donante se visualiza a través del apósito transparente, y si no hay necesidad, no se cambia hasta transcurridos 7-10 días. A la retirada de las suturas se procede, como norma general, durante la segunda semana.

El grado de dolor experimentado en el procedimiento y en cada cura se registra a través de la escala visual analógica (EVA).

Para evaluar de manera más objetiva la aceptación del tratamiento, los pacientes responden a un cuestionario de satisfacción al término del procedimiento (alta médica).

\section{RESULTADOS}

Durante el período de tiempo de estudio, la frecuentación en cuanto a revisiones totales fue de 695 días, sobre un total de 15 pacientes, obteniéndose una media de $46,33( \pm 39,18)$ intervenciones por usuario con una frecuencia de 2 días por semana/usuario. La media de edad fue de 46,93 años $(\mathrm{R}=18 / 75=57)$. Distribución por sexo: 9 hombres y
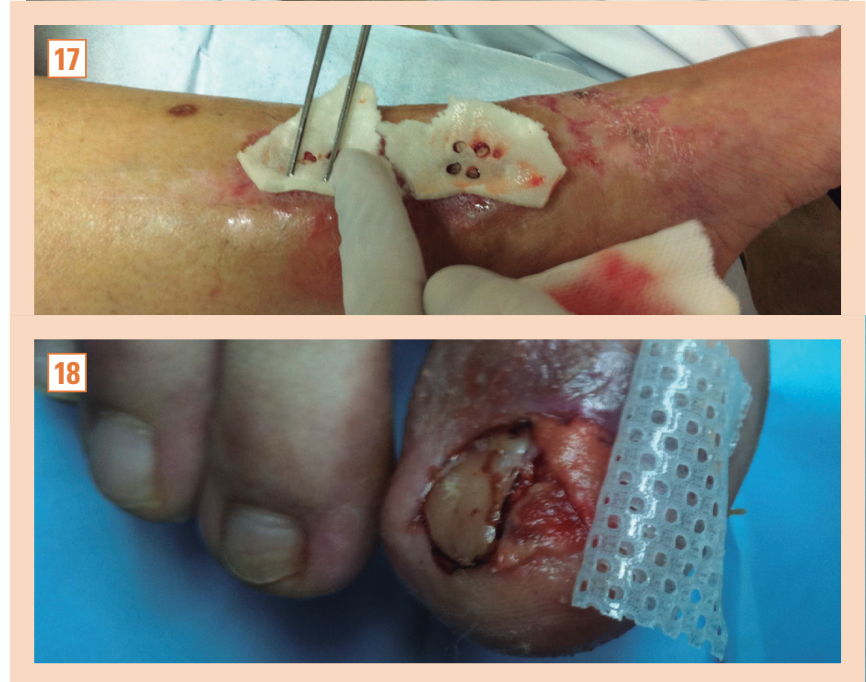

Figuras 17 y 18. Colocación de injertos de Reverdin sobre el lecho con plasma rico en plaquetas y en un nido de apósito de colágeno-COR. Protección con apósito de malla de silicona.

6 mujeres. La fase de cicatrización al comienzo del tratamiento es predominantemente inflamatoria (86,67\%) (fig. 19).

Se realizaron por término medio 5,67 injertos en isla por paciente (fig. 20), de los que presentaron viabilidad visible, transcurridas 3 semanas, el 75\% de ellos (fig. 21). El PRP se aplicó, de media, 2,67 veces por paciente, y el rango de extensión del área tratada fue de $1,5-70 \mathrm{~cm}^{2}$ (fig. 22). El cierre completo de las heridas tratadas se consiguió en el 93,3\% de los casos; solo un paciente de los 15 requirió derivación al Servicio de Cirugía Plástica para estudio, y fue a petición propia (fig. 23).

El nivel del dolor experimentado por los pacientes durante los procedimientos (fig. 24) alcanza en la EVA una media de 1,6. El grado de satisfacción obtenido es elevado (fig. 25), teniendo en cuenta que parte de los pacientes presentaban, al inicio del estudio, heridas persistentes, sin respuesta al tratamiento convencional, de incluso más de un ańo de evolución (tabla 1). No se observaron efectos adversos durante la fase del tratamiento. 


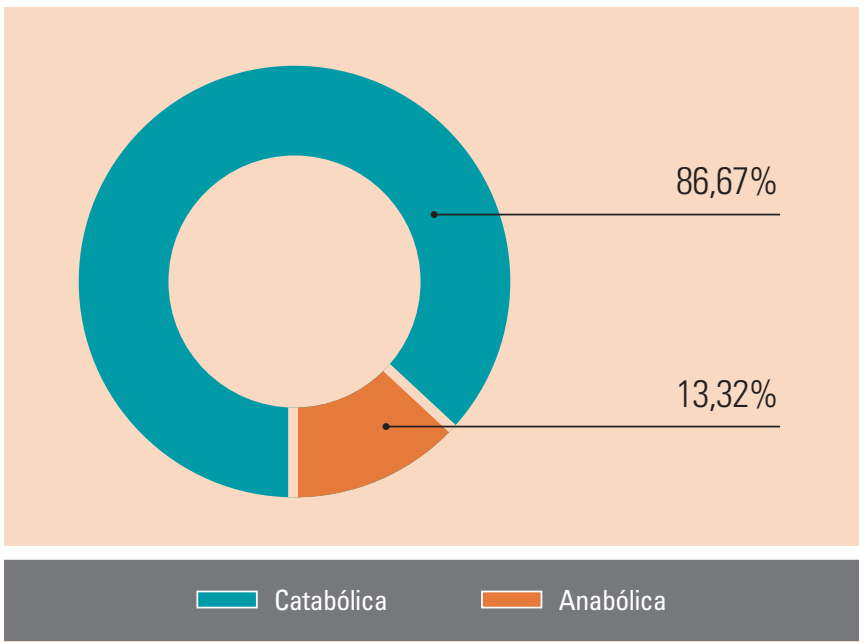

Figura 19. Fase inicial de la cicatrización al comienzo del tratamiento con plasma rico en plaquetas.

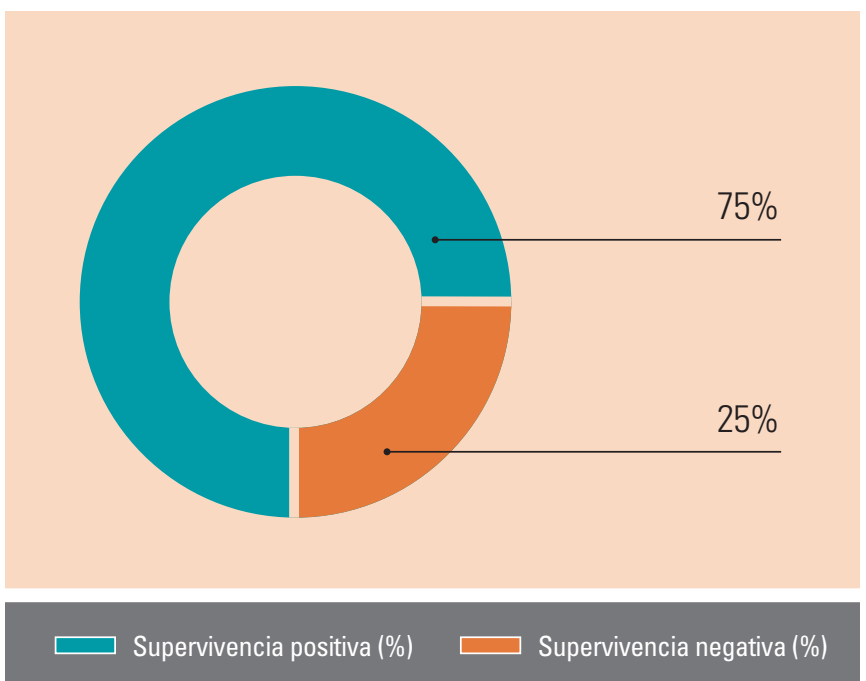

Figura 21. Viabilidad de los injertos al cabo de 3 semanas del tratamiento.

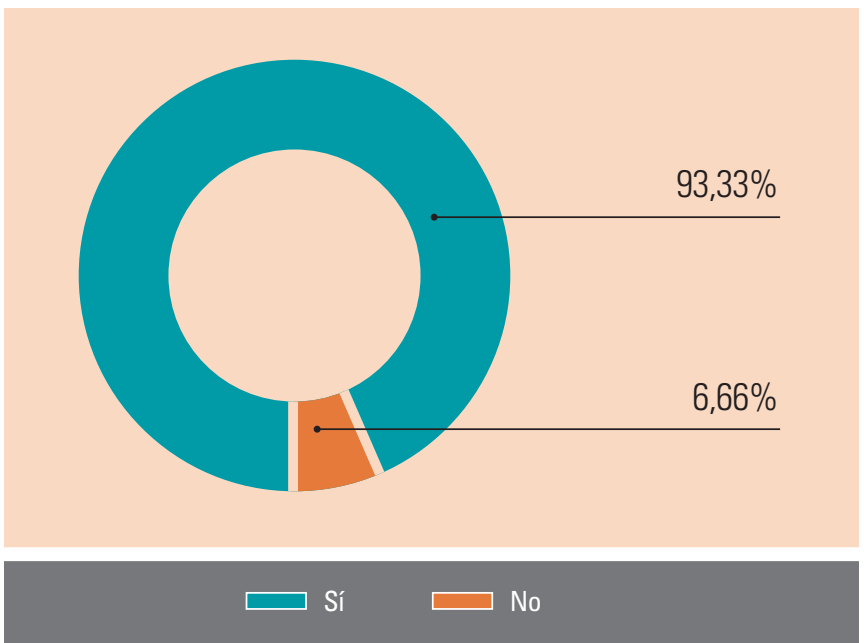

Figura 23. Total de pacientes con cierre definitivo de heridas tratadas con plasma rico en proteínas + injerto.

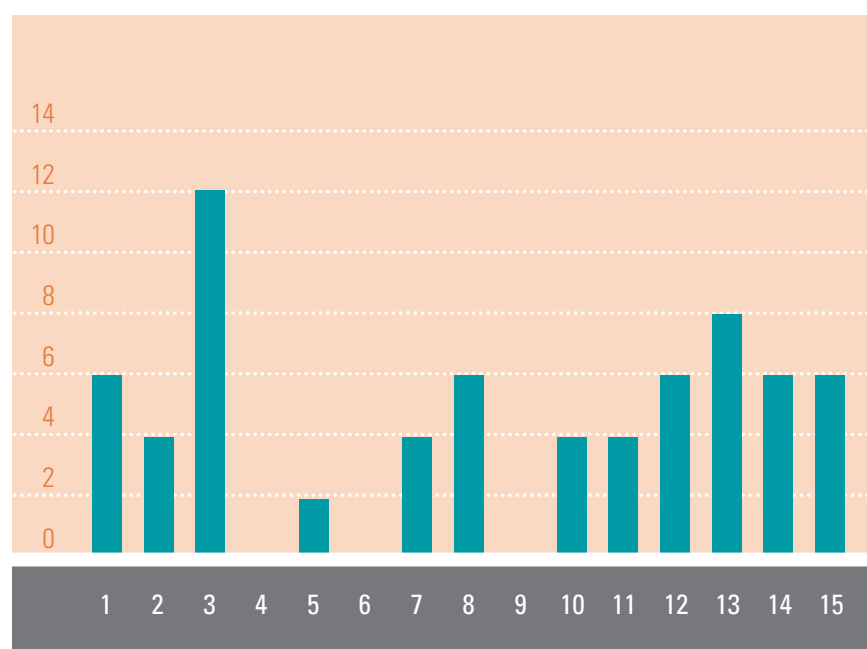

Figura 20. Cantidad de injertos aplicados a cada paciente.

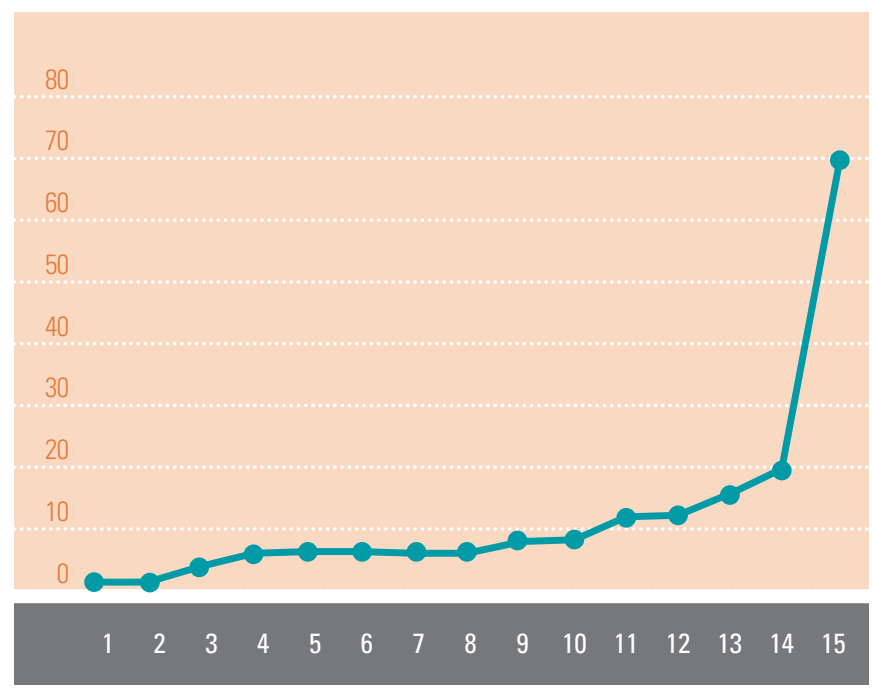

Figura 22. Área de lesión $\left(\mathrm{cm}^{2}\right)$ por paciente.

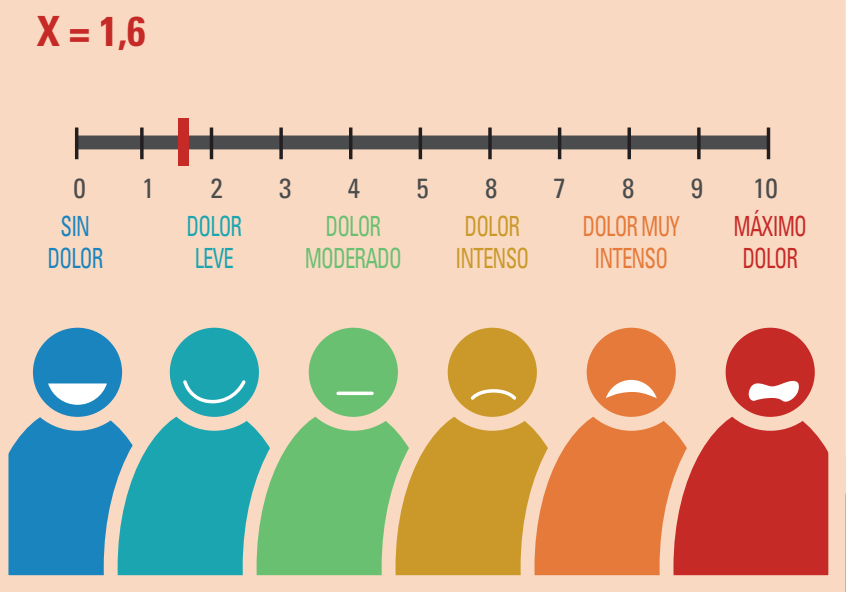

Figura 24. Escala visual analógica (EVA) de intensidad del dolor. 


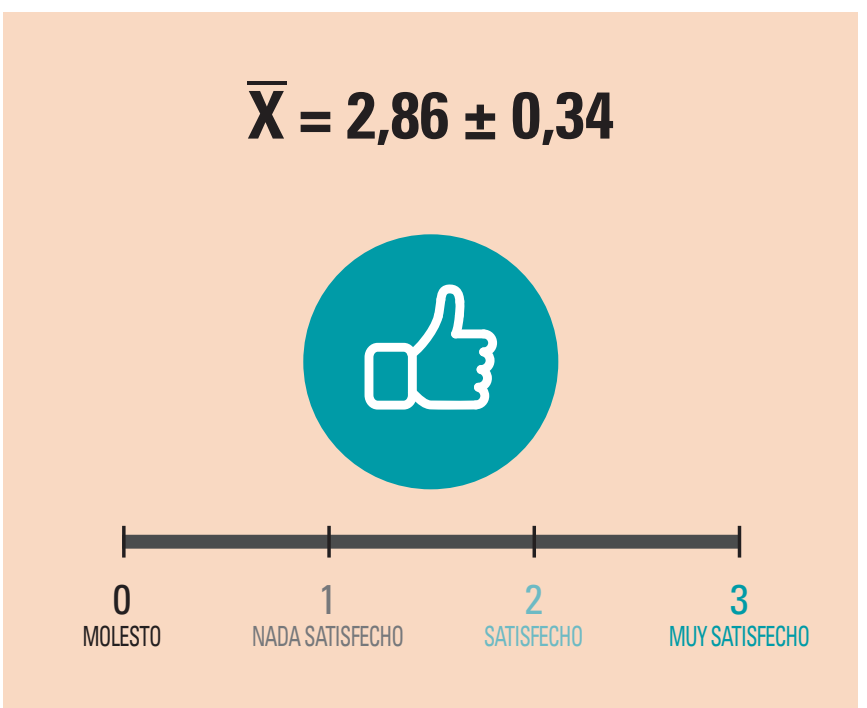

Figura 25. Grado de satisfacción del paciente.

Tabla 1. Grado inicial de la lesión al principio del tratamiento

\begin{tabular}{|c|c|}
\hline Grado de lesión al inicio & Porcentaje de pacientes \\
\hline I & 0 \\
\hline II & 20 \\
\hline II & 40 \\
IV & 40 \\
\hline
\end{tabular}

\section{$У$ CONCLUSIONES}

Los resultados obtenidos sugieren que la aplicación conjunta de injertos de Reverdin y PRP es eficaz e inocua. La epitelización definitiva de la herida crónica, utilizando este diseńo, se ha conseguido en la casi totalidad de los casos, mediante un cierre completo, aunque presenta una aparente variabilidad en el tiempo necesario, en relación con:

- El tamaño y la profundidad de la lesión (grado).

- La existencia de contaminación en el lecho de la herida.

- La fase de la cicatrización inicial (necesaria la granulación previa, estimulada por aplicación de PRP).

- Región anatómica de la herida crónica.

- Cantidad del PRP aplicado.

El elevado grado de satisfacción obtenido por los pacientes expresa de forma evidente la gran aceptación de la metodología propuesta. Como aspectos más relevantes destacamos que:

- Es una técnica poco cruenta y sin grandes procedimientos quirúrgicos.

- El dolor que experimenta el paciente es mínimo.

- Se evitan derivaciones a otros servicios para el tratamiento quirúrgico.

- No se observa la aparición de efectos adversos importantes durante la aplicación del método.

- Es asequible en cualquier centro sanitario (atención primaria en cirugía menor ambulatoria), con un mínimo de recursos materiales y humanos, aunque solo factible con un entrenamiento preciso del personal que lo realiza.

Es necesario realizar ensayos clínicos aleatorizados más ambiciosos, y verificar la disminución del tiempo necesario hasta el cierre completo de la herida, comparando el coste generado durante el período de tratamiento respecto al método tradicional de cura húmeda, así como las posibles complicaciones a más largo plazo

\section{BIBLIOGRAFÍA}

1. Calderón W Historia de la cirugía plástica mundial. Cirugía Plástica. Santiago: Sociedad de Cirujanos de Chile; 2001. p. 19-27.

2. Krizek T, Harries R, Robson M. Biology of tissue injury and repair. En: Georgiade R, Riefkohl L, Levin S, editores. Plastic, Maxillofacial and Reconstructive Surgery. 3. ${ }^{a}$ ed. Baltimore: Williams and Wilkins; 1997. p. 3-9.

3. Reverdin JL. Greffe epidermique-Experience faite dans le service de M. le docteur Guyon, àl'hôpital Necker. Plast Reconstr Surg. 1968:41:79-82.

4. Gualdi G, Monari P, Farisoglio C, Calzavara-Pinton P. Nested graft in chronic wounds: a new solution for an old problem. Int Wound J. 2011;8(2):127-31.

5. Beca T, Hernández G, Morantes S, Bascones A. Plasma rico en plaquetas. Una revisión bibliográfica. Av Periodon Implantol Oral. 2007:19(1):39-52

6. Arquero Salinero P. Plasma rico en plaquetas en cirugía estética. Cirugía Estética y Plástica. 2009:5(9):42-8.

7. Centella T, Oliva E, García J, Huélamo T, Lamas MJ, Maseda R, et al. Tratamiento de las heridas infectadas tras cirugía cardia- ca con la utilización de plasma rico en factores de crecimiento. Resultados preliminares. Anales de Cirugía Cardíaca y Vascular. 200511(4):208-13.

8. Mittermayr R, Bransky L, Moritz M, Jeschke MG, Herndon DN, Traber $D$, et al. Fibrin biomatrix-conjugated platelet -derived growth factor $A B$ accelerates wound healing in severe thermal injuries. J Tissue Eng Regen Med. 2013;May 31.doi.10.1002/term.1749.

9. Wrotoniak M, Bielecki T, Gazdzik TS. Current opinion about using the platelet rich gel in othopaedics and trauma surgery. Ortop Traumatol Rehabil. 2007:9(3):227-38.

10. Sánches M. El Plasma rico en plaquetas: ¿una moda 0 una realidad? Archivos de Medicina del Deporte. 2010;27(138):252-54.

11. McAndrews PA. Meniscal repair enhacement techniques. Clinics in Sport Medicine. 199615(3):499-510.

12. Burton SA, Honor DJ. The role of platelets in inflammation and body defense. The Compedium Small Animal. 1981:13:1129-37.

13. Anitua E. Un nuevo enfoque en la regeneración ósea. Plasma Rico en Factores de Crecimiento (PRGF). 1. ${ }^{\text {a }}$ ed. Vitoria: Puesta al día Publicaciones; 2000. p. 51-145.
14. Marx RE. Platelet-rich plasma (PRP): what is PRP and what is not PRP? Implant Dent 2001;10:225-8. doi: 10.1097/00008505200110000-00002

15. Dhillon RS, Scwuarz EM, Maloney MD. Platelet-rich plasma therapy-future or trend? Artrhitis Res Ther. 2012;14(4):219.

16. Marlo MM. Actualización de la técnica de obtención y uso del Plasma Rico en Factores de Crecimiento (PRGF). Revista Dental de Chile;agosto:2002;25-8.

17. Sáez-Torres C, Calvo J, Gayá A. Calidad del plasma rico en plaquetas: Estudio de la activación plaquetaria. Revista Española de Cirugía Oral y Maxilofacial, 2007;26(4):240-48

18. Arvelo F, Cotte C. Metaloproteasas en la progresión tumoral. Revisión. Invest Clín. 2006;47(2):185-205.

19. Shultz G, Sibbald R, Falanga V. Wound bed preparation: a systematic approach to wound management. Wound Rapair Regen. 2003:11(2):28.

20. Moffatt C, Soldevilla Agreda J. Preparación del lecho de la herida en la práctica. European Wound Management Association, 2004 